\title{
Modelling the influence of preventive maintenance on protection system reliability performance
}

\author{
S.T.J.A. Vermeulen \\ Eindhoven University of \\ Technology \\ P.O. Box 513 \\ 5600 MB Eindhoven \\ The Netherlands
}

\author{
H. Rijanto \\ Eindhoven University of \\ Technology \\ P.O. Box 513 \\ 5600 MB Eindhoven \\ The Netherlands
}

\author{
F.A. van der Duyn Schouten \\ Tilburg University \\ P.O. Box 90153 \\ 5000 LE Tilburg \\ The Netherlands
}

\begin{abstract}
Protection systems exhibit two important types of failures: failures to operate and unwanted operations. Both failure modes have been introduced in a model description designed for the evaluation of the influence of preventive maintenance on protection system reliability performance. The model description is constructed as a continuous time Markov chain. The system states and the transitions between states are generated in a general and systematic manner which makes it possible to apply the model description to a lot of different situations. Through an example it is shown that (the quality) of preventive maintenance can have significant influence upon the reliability performance of a given system.
\end{abstract}

Keywords: Reliability Modeling, Markov Processes, Power System Protection, Power System Maintenance

\section{INTRODUCTION}

In the past there has been paid considerable attention towards reliability aspects of protection systems $[1,2,3,4$, $5,6,7,8,9,10]$. A major reason for this is the fact that failures of protection systems can have considerable impact on the continuity of the supply. Whenever a fault occurs the protection system should react in such a way that only the faulted part of the power system becomes isolated in order to preserve as much of the power system's supply abilities to customers. The isolation of the faulted component should be performed as fast as possible in order to prevent neighboring power system components from excessive damage due to too high currents and voltages.

PE-053-PWRD-0-11-1997 A paper recommended and approved by the IEEE Power System Relaying Committee of the IEEE Power Engineering Society for publication in the IEEE Transactions on Power Delivery. Manuscript submilted April 8, 1997; made available for printing November 11, 1997.
The major elements of a protection system are the input transducers, protective relays, circuit breakers and if necessary communication systems. In a lot of studies the failure properties of these elements are lumped together and are indicated as failures of the protection system. With respect to these lumped protection systems two important failure modes can be distinguished: the failure to operate mode and the unwanted operation mode.

\section{Failure to operate}

When a fault occurs the protection system controlling the faulted component should isolate this component as fast as possible. When a protection system fails to operate a backup protection system should react in order to isolate the fault. This corrective action by a backup protection system usually has some operational disadvantages: it is likely that along with the faulted component also some healthy system parts are removed from service. Because a switch off action by a backup protection system usually takes more time there might also be more damage done to healthy system parts. When a protection system does not respond to a system fault in its protected zone the protection system is said to be dormant. Because protection systems are most of the time operating in a passive standby mode a dormant state of a protection system can remain unrevealed for quite some time. The occasions at which failures to operate reveal themselves are during system faults and preventive maintenance operations.

\section{Unwanted operation (maltrip)}

A protection system can also perform unnecessary switching operations. These failures should also be prevented from as much as possible because they might also have negative implications on the continuity of the supply. A maltrip might for example originate from a protection system defect that turns into a maltrip at the occurrence of some power system event [10]. When a protection system exhibits a fault such that it will maltrip whenever certain input conditions occur the protection system is said to be in a potential maltrip state. Potential maltrips might be detected during preventive maintenance before they turn into real maltrips due to some power system event. 
Both types of protection system failures have been included in a stochastic model description which is specifically designed for the evaluation of protection system reliability performance as a function of preventive maintenance parameters (frequency, duration).

\section{THE MODEL DESCRIPTTON}

A stochastic model description has been developed describing power system components (e.g. power lines or power cables) that are being protected by main and backup protection systems. The components are either up (in good condition) or down (out of service after having failed until having been repaired). Protection systems can be in 3 conditions: they can be in optimal condition, potentially failing to operate, or potentially maltripping. Potential failures to operate represent defects that for some specific system faults will result in a real failure to operate; the protection system is dormant with respect to certain system faults. Other failures are correctly being switched off despite the protection system defect. Apart from the 3 possible technical states the protection systems can be out of service for preventive maintenance resulting in a total of 6 possible states for each protection system.

Before the model description is being presented a list of symbols is given.

C a protected component

$\lambda_{\mathrm{mX}}$ rate of occurrence of potential maltrips of protection system X [defects/year]

$\lambda_{\mathrm{fX}}$ rate of occurrence of potential failures to operate of protection system $X$ [defects/year]

$\lambda_{X} \quad$ rate at which system events occur that turn potential maltrips of protection system $\mathrm{X}$ into real maltrips [failures/year]

$\lambda_{C}$ failure rate of component $C$ [failures/year]

$\mu_{\mathrm{X}} \quad$ rate at which preventive maintenance on protection system $\mathrm{X}$ is started [occasions/year]

$\theta_{\mathrm{X}}$ rate at which preventive maintenance on protection system $\mathrm{X}$ is being completed [occasions/year]

$\varrho_{C}$ repair rate of component $\mathrm{C}$ [repairs/year of downtime]

$\mathrm{p}_{\mathrm{fXC}} \quad$ probability of a real failure to operate when protection system $\mathrm{X}$ is potentially failing to operate and $\mathrm{C}$ goes down

$\mathrm{p}_{\mathrm{mXC}}$ probability of a real maltrip when protection system $\mathrm{X}$ is potentially maltripping and $\mathrm{C}$ goes down

$\epsilon_{\mathrm{fX}} \quad$ the fraction of potential failures to operate that are detected during preventive maintenance on protection system $\mathrm{X}$

$\epsilon_{\mathrm{mX}}$ the fraction of potential maltrips that are detected during preventive maintenance on protection system $\mathrm{X}$

\section{$=\quad$ indication of a protection system being in optimal condition \\ $+\quad$ indication of a protection system being in a poten- tial maltrip state indication of a protection system being in a poten- tial failure to operate state \\ M indication of a protection system being out of service for preventive maintenance}

The model description has been developed as a continuous time Markov chain [12]. The following assumptions and approximations have been used for constructing the model:

- the transition times (times to occurrences of failures, component repair times, preventive maintenance times and times between subsequent preventive maintenance actions) are exponentially distributed random variables.

- protection system defects and component failures are sindependent. However, for example $\mathrm{p}_{\mathrm{mXC}}$ might be chosen such that it accounts for the possible extra high risk of a certain protection system maltripping after occurrence of a nearby fault that is outside the (main) protective range of protection system $X$.

- a protection system can only exhibit one potential failure mode at a given time.

- protection systems cannot become defective during repairs (a component being down). When a component is down the process can only move to some up-state at a corresponding repair rate.

- the time needed to repair (replace) a protection system is neglected in favor of a state space reduction. After the occurrence of a real protection system failure the process moves to a state in which the protection system is in optimal condition again. The time needed to carry out preventive maintenance is not neglected in order to be able to evaluate the effects related to a protection system being unable to perform its protective task because of preventive maintenance.

- when a protection system exhibits a certain defect this defect might be detected and corrected during preventive maintenance (with probability $\epsilon_{\mathrm{mX}}$ or $\epsilon_{\mathrm{fX}}$, depending on the type of failure). Although during preventive maintenance certain protection system defects might remain unrevealed preventive maintenance is supposed not to cause any extra defects.

when in case of a fault the protection system behaves correctly a possible defect of this particular protection system is not being detected during the repair of the failed power system apparatus.

The model description is created using a general and systematic approach which makes it possible to evaluate a lot of different situations. The model states are composed 
of the single component: and protection system states. The state space of the model contains in principle all possible combinations of protection system and component states that fit within the model. assumptions. In case of 1 component that is being proterted by 2 protection systems (main and backup) this results in a total of 45 model states. In some specific cases some combinations of protection system and component states cannot occur in practice. When e.g. 2 protection systems are always being taken out of service for preventive maintenance at the same time the model states in which only 1 of them is taken out of service for preventive maintenance can be excluded from the model. The transitions between model states are described quite generally, based upon the states of the individual protection systems and components.

Let us first assume that all components are up. When a protection system $X$ is in an optimal condition it may enter a potential maltrip state at a rate $\lambda_{\mathrm{mX}}$, a potential failure to operate state at a rate $\lambda_{1 X}$ or a preventive maintenance state at a rate $\mu_{X}$. From a potential maltrip state the protection system can either perform a real maltrip (at a rate $\lambda_{X}$ ) or it might enter a preventive maintenance state (at a rate $\mu_{X}$ ). From a potential failure to operate state the protection system can only enter a preventive maintenance state (at a rate $\left.\mu_{X}\right)$. When a protection system is potentially failing to operate (potentially maltripping) the defect is either detected during preventive maintenance after which the protection system is brought back: into optimal condition at a rate $\epsilon_{\mathrm{f} X} \theta_{\mathrm{X}}\left(\epsilon_{\mathrm{m} X}{ }^{\theta_{\mathrm{X}}}\right)$ or the defect remains unrevealed causing the protection system to be returned into service defectively at a rate $\left.\left(1-\epsilon_{\mathrm{fX}}\right) \theta_{\mathrm{X}}\left(\left(1-\epsilon_{\mathrm{mX}}\right) \Theta_{\mathrm{X}}\right)\right)$.

Let us now assume that component $\mathrm{C}$ goes down (at a rate $\lambda_{C}$ ). If the main and backup protection systems of $C$ all are in optimal condition the stochastic process moves to a state in which $C$ is being repaired and restored to service again (brought back into the up-state at a rate $\varrho_{C}$ ). If some of the main and backup protection systems are defective, however, there are several possible repair transitions to upstates depending upon the behavior of the defective protection systems. Let us assume for example that a component $\mathrm{C}$ is protected by a main protection system $\mathrm{P}$ and a backup protection system $B$ and let us assume that $P$ is potentially failing to operate and $B$ is potentially maltripping. When $C$ fails there are 3 possibilities: $P$ might indeed fail to operate after which $B$ is forced to act (the tendency of $B$ to perform a maltrip is not observed/detected because $B$ is forced to act after $\mathrm{P}$ exhibited a failure to operate), $\mathrm{P}$ performs the correct switching action in spite of the potential failure state but $\mathrm{B}$ also performs a maltrip or $\mathrm{P}$ performs a correct switching action while $B$ does not perform a maltrip. With respect to the first possibility the process moves to a state in which both $\mathrm{C}$ and $\mathrm{P}$ are repaired at a rate $\mathrm{p}_{\mathrm{fPC}} \mathrm{Q}_{\mathrm{C}}$, with respect to the second possibility the process moves to a state in which both $\mathrm{C}$ and $\mathrm{B}$ are repaired at a rate (1$\left.\mathrm{p}_{\mathrm{fPC}}\right) \mathrm{p}_{\mathrm{mBC}} \mathrm{e}_{\mathrm{C}}$ and with respect to the third possibility the process moves to a state in which only $\mathrm{C}$ is repaired at a rate $\left(1-\mathrm{p}_{\mathrm{fPC}}\right)\left(1-\mathrm{p}_{\mathrm{mBC}}\right) Q_{\mathrm{C}}$.

The solution of a continuous time Markov chain, the vector of state probabilities, consists of both a transient part and a steady state part. In a lot of reliability studies only the steady state part of the solution is being considered [1, $2,3,4,5]$. This of course always is an approximation since the economic life of any technical installation is finite. However, certainly in case of low transition rate values it may take quite some time before the steady state is reached. To find out whether or not in a certain case the total solution could be approximated by only using the steady state part of the solution the transient part has been investigated by using the modified Jensen's method [11]. For the ease of analysis and comparison of results only situations have been evaluated in which the model solution could be approximated within given limits by just considering the steady state part of the solution.

\section{REWARD STRUCTURE}

To evaluate and compare different situations some reward (cost) structure has been added to the model description. With respect to the model description several cost contributions have been distinguished:

$c_{\text {maint }(X)}$ : costs of carrying out preventive maintenance in case no defect is being found (protection system $X$ is either in optimal condition or the protection system defect remains unrevealed during preventive maintenance)

$c_{\text {maint }(m, X)}\left(c_{\text {maint }(f, X)}\right)$ : costs of carrying out preventive maintenance on $X$ in case a potential maltrip (failure to operate) defect is being found

$c_{\text {int(C) }}$ : costs attached to the interruption of the supply because of a failure of $\mathrm{C}$

$c_{\text {int }(m, X)}\left(c_{\text {int }(f, X)}\right)$ : costs attached to the interruption of the supply because protection system $X$ performs a maltrip (failure to operate)

$c_{\text {rep(C) }}$ : costs attached to the repair of component $C$

$c_{\text {rep }(X)}$ : costs attached to the repair/replacement of protection system $X$

The cost contributions have been treated as event related costs. This means that costs have been attached to the transitions that occur between certain states. This choice is made instead of attaching costs to state probabilities (time fraction related costs) because the costs are not proportional with the fraction of time the process spends in a certain state. For example after a component failure occurs the supply to the interrupted customers might be restored 
through switching to an alternative network configuration while the component is under repair (the component remains in the down state until having been repaired).

With respect to the costs related to carrying out of preventive maintenance distinction is made between the situation in which no protection system defect is being found and the situation in which the protection system is found to be defective because in the latter case repair/replacement is needed resulting in higher costs. So when a protection system $X$ is in a potential maltrip (failure to operate) state the defect is being detected through maintenance at a rate $\epsilon_{\mathrm{mX}_{X}} \mu_{\mathrm{X}}\left(\epsilon_{\mathrm{fX}} \mu_{\mathrm{X}}\right)$ and the defect remains unrevealed during preventive maintenance at a rate (1$\left.\epsilon_{\mathrm{mX}}\right) \mu_{\mathrm{X}}\left(\left(1-\epsilon_{\mathrm{fX}}\right) \mu_{\mathrm{X}}\right)$. Similarly, when e.g. the failure to operate of protection system $X$ in case of failure of component $\mathrm{C}$ implies certain costs then these costs are found at a rate $p_{f X C} \lambda_{C}$. Details of event related costs implemented in continuous time Markov chains can be found in [12].

\section{APPLICATION OF THE MODEL DESCRIPTION}

As an example application let us consider a power system component $\mathrm{C}$ that is protected by a main protection system and a (local) backup protection system. The model description can be used to evaluate the reliability performance of both the main and the backup relay. With respect to this particular situation it is assumed that primary protection $P$ and backup protection $B$ are always being taken out of service for preventive maintenance at the same time. It is assumed that the rate at which preventive maintenance on both protections is being completed, $\theta$, equals the smallest value of $\theta_{\mathrm{P}}$ and $\theta_{\mathrm{B}}$. A description of the model states and the transitions between the model states is given in table 1 . The following parameter values have been used:

$\lambda_{\mathrm{mP}}=0.08$ per year

$\lambda_{\mathrm{mB}}=0.09$ per year

$\lambda_{\mathrm{fP}}=0.4$ per year

$\lambda_{\mathrm{fB}}=0.5$ per year

$\lambda_{\mathrm{P}}=\lambda_{\mathrm{B}}=20$ per year

$\lambda_{\mathrm{C}}=0.1$ per year

$\theta=\theta_{P}=\theta_{B}=0.25$ per hour

$\mathrm{e}_{\mathrm{C}}=1$ per day

$\mathrm{p}_{\mathrm{fPC}}=\mathrm{p}_{\mathrm{fBC}}=0.99$

$\mathrm{p}_{\mathrm{mPC}}=0$

$\mathrm{p}_{\mathrm{mBC}}=0.05$

$c_{\text {maint }(P)}=c_{\text {maint }(B)}=1$

$c_{\text {maint }(m, P)}=c_{\text {maint }(m, B)}=c_{\text {maint }(f, P)}=c_{\text {maint }(f, B)}=2$

$c_{\text {int }(C)}=20$

$c_{\text {int }(m, P)}=c_{\text {int }(f, P)}=0$

$c_{\text {int }(m, B)}=c_{\text {int }(f, B)}=120$

$c_{\text {rep }(C)}=10$
$c_{\operatorname{rep}(P)}=c_{\text {rep }(B)}=3$

The values of $\mu_{\mathrm{P}}, \mu_{\mathrm{B}}, \epsilon_{\mathrm{mP}}, \epsilon_{\mathrm{fP}}, \epsilon_{\mathrm{mB}}$ and $\epsilon_{\mathrm{fB}}$ will be treated as variables.

The costs have been expressed as relative values: each of the cost factors has been related to the costs of carrying out the preventive maintenance procedure (in case no defect is being found). The rates $\lambda_{\mathrm{mB}}$ and $\lambda_{\mathrm{fB}}$ are chosen higher than $\lambda_{\mathrm{mP}}$ and $\lambda_{\mathrm{fP}}$ respectively because $\mathrm{P}$ and $\mathrm{B}$ will be different relays and it seems logical to use the protection with the best (reliability) performance as the main protection. The probability $p_{m P C}$ is set to 0 because when $C$ fails $P$ should initiate a trip to isolate the fault (the trip is seen as a correct action so the potential maltrip defect cannot be recognized).

In fig. 1 costs as a function of the maintenance frequency $\mu=\mu_{\mathrm{P}}=\mu_{\mathrm{B}}$ are shown for different values of the preventive maintenance effectiveness $\epsilon=\epsilon_{\mathrm{mP}}=\epsilon_{\mathrm{mB}}=\epsilon_{\mathrm{fP}}=\epsilon_{\mathrm{fB}}$. It is to be observed that in case the preventive maintenance effectiveness increases the optimal maintenance frequency becomes a little smaller. This is intuitively clear because if preventive maintenance becomes more effective less defects remain unrevealed reducing the need for (additional) preventive maintenance to find them. The situation in which the preventive maintenance is more effective results in the smaller amount of costs because of the fact that less inspections are needed to detect a defect before this defect can turn into a real failure. Furthermore it is shown that significant cost reduction might be obtained by optimising the maintenance frequency $\mu$. It is to be noted that the range of $\mu$-values is chosen such that the difference between the transient state probabilities after 10 years and the state probabilities belonging to the steady state solution is less than $15 \%$ (the process starts in the state in which all protections, $\mathrm{P}$ and $\mathrm{B}$, and components, $\mathrm{C}$, are in optimal condition).

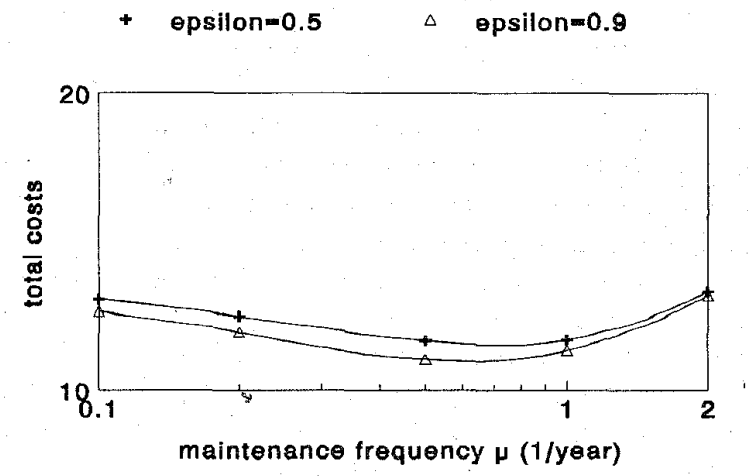

Fig 1.: Total costs versus the frequency at which preventive maintenance is carried out on both $\mathrm{P}$ and $\mathrm{B}$ 
Table 1: The states of the Markov model and the transitions between the states.

\begin{tabular}{|c|c|c|c|c|}
\hline state & $\mathbf{P}$ & Es & $\mathrm{C}$ & next state (transition rate) \\
\hline 1 & + & + & up & $2\left(\lambda_{\mathrm{P}}\right), 4\left(\lambda_{\mathrm{B}}\right), 10\left(\lambda_{\mathrm{C}}\right), 19\left(\mu_{\mathrm{P}}\right), 28\left(\mu_{\mathrm{B}}\right)$ \\
\hline 2 & $=$ & + & up & $1\left(\lambda_{\mathrm{mP}}\right), 3\left(\lambda_{\mathrm{fP}}\right), 5\left(\lambda_{\mathrm{B}}\right), 11\left(\lambda_{\mathrm{C}}\right), 20\left(\mu_{\mathrm{P}}\right), 29\left(\mu_{\mathrm{B}}\right)$ \\
\hline 3 & - & + & up & $6\left(\lambda_{\mathrm{B}}\right), 12\left(\lambda_{\mathrm{C}}\right), 21\left(\mu_{\mathrm{P}}\right), 30\left(\mu_{\mathrm{B}}\right)$ \\
\hline 4 & + & $:=$ & up & $1\left(\lambda_{\mathrm{mB}}\right), 5\left(\lambda_{\mathrm{P}}\right), 7\left(\lambda_{\mathrm{fB}}\right), 13\left(\lambda_{\mathrm{C}}\right), 22\left(\mu_{\mathrm{P}}\right), 31\left(\mu_{\mathrm{B}}\right)$ \\
\hline 5 & $=$ & $:=$ & up & $2\left(\lambda_{\mathrm{mB}}\right), 4\left(\lambda_{\mathrm{mP}}\right), 6\left(\lambda_{\mathrm{fP}}\right), 8\left(\lambda_{\mathrm{fB}}\right), 14\left(\lambda_{\mathrm{C}}\right), 23\left(\mu_{\mathrm{P}}\right), 32\left(\mu_{\mathrm{B}}\right)$ \\
\hline 6 & - & $:=$ & up & $3\left(\lambda_{\mathrm{mB}}\right), 9\left(\lambda_{\mathrm{fB}}\right), 15\left(\lambda_{\mathrm{C}}\right), 24\left(\mu_{\mathrm{p}}\right), 33\left(\mu_{\mathrm{B}}\right)$ \\
\hline 7 & + & - & up & $8\left(\lambda_{\mathrm{P}}\right), 16\left(\lambda_{\mathrm{C}}\right), 25\left(\mu_{\mathrm{P}}\right), 34\left(\mu_{\mathrm{B}}\right)$ \\
\hline 8 & $=$ & - & up & $7\left(\lambda_{\mathrm{mP}}\right), 9\left(\lambda_{\mathrm{fP}}\right), 17\left(\lambda_{\mathrm{C}}\right), 26\left(\mu_{\mathrm{P}}\right), 35\left(\mu_{\mathrm{B}}\right)$ \\
\hline 9 & - & - & up & $18\left(\lambda_{\mathrm{C}}\right), 27\left(\mu_{\mathrm{p}}\right), 36\left(\mu_{\mathrm{B}}\right)$ \\
\hline 10 & + & + & down & $1\left(\left(1-p_{m B C}\right) e_{C}\right), 4\left(p_{m B C} e_{C}\right)$ \\
\hline 11 & $=$ & + & down & $2\left(\left(1-p_{\mathrm{mBC}}\right) e_{\mathrm{C}}\right), 5\left(\mathrm{p}_{\mathrm{mBC}} e_{\mathrm{C}}\right)$ \\
\hline 12 & - & + & down & $2\left(p_{\mathrm{fPC}} e_{\mathrm{C}}\right), 3\left(\left(1-\mathrm{p}_{\mathrm{fPC}}\right)\left(1-\mathrm{p}_{\mathrm{mBC}}\right) e_{\mathrm{C}}\right), 6\left(\left(1-\mathrm{p}_{\mathrm{fPC}}\right) \mathrm{p}_{\mathrm{mBC}} e_{\mathrm{C}}\right)$ \\
\hline 13 & + & $=$ & down & $4\left(e_{C}\right)$ \\
\hline 14 & $=$ & $:=$ & down & $5\left(\mathrm{Q}_{\mathrm{C}}\right)$ \\
\hline 15 & - & $:=$ & down & $5\left(\mathrm{p}_{\mathrm{fPC}} \varrho_{\mathrm{C}}\right), 6\left(\left(1-\mathrm{p}_{\mathrm{fPC}}\right) \varrho_{\mathrm{C}}\right)$ \\
\hline 16 & + & $\therefore$ & down & $7\left(e_{C}\right)$ \\
\hline 17 & $=$ & .. & down & $8\left(e_{C}\right)$ \\
\hline 18 & - & - & down & $5\left(p_{\mathrm{fPC}} \mathrm{p}_{\mathrm{fBC}} \mathrm{e}_{\mathrm{C}}\right), 8\left(\mathrm{p}_{\mathrm{fPC}}\left(1-\mathrm{p}_{\mathrm{fBC}}\right) e_{\mathrm{C}}\right), 9\left(\left(1-\mathrm{p}_{\mathrm{fPC}}\right) e_{\mathrm{C}}\right)$ \\
\hline 19 &,$+ \mathrm{M}$ &,$+ M$ & up & $1\left(\left(1-\epsilon_{\mathrm{mP}}\right)\left(1-\epsilon_{\mathrm{mB}}\right) \theta\right), 2\left(\epsilon_{\mathrm{mP}}\left(1-\epsilon_{\mathrm{mB}}\right) \theta\right), 4\left(\left(1-\epsilon_{\mathrm{mP}}\right) \epsilon_{\mathrm{mB}} \theta\right), 5\left(\epsilon_{\mathrm{mP}} \epsilon_{\mathrm{mB}} \theta\right)$ \\
\hline 20 & $=, M$ &,$+ M$ & up & $2\left(\left(1-\epsilon_{\mathrm{mB}}\right) \theta\right), 5\left(\epsilon_{\mathrm{mB}} \theta\right)$ \\
\hline 21 &,$- \mathbf{M}$ &,$+ M$ & up & $2\left(\epsilon_{\mathrm{fP}}\left(1-\epsilon_{\mathrm{mB}}\right) \theta\right), 3\left(\left(1-\epsilon_{\mathrm{fP}}\right)\left(1-\epsilon_{\mathrm{mB}}\right) \Theta\right), 5\left(\epsilon_{\mathrm{fP}} \epsilon_{\mathrm{mB}} \Theta\right), 6\left(\left(1-\epsilon_{\mathrm{fP}}\right) \epsilon_{\mathrm{mB}} \Theta\right)$ \\
\hline 22 &,$+ \mathrm{M}$ & $=, M$ & up & $4\left(\left(1-\epsilon_{\mathrm{mP}}\right) \theta\right), 5\left(\epsilon_{\mathrm{mP}} \theta\right)$ \\
\hline 23 & $=, M$ & $=, \mathbf{M}$ & up & $5(\theta)$ \\
\hline 24 &,$- \mathbf{M}$ & $=, \mathrm{M}$ & up & $5\left(\epsilon_{\mathrm{fP}} \theta\right), 6\left(\left(1-\epsilon_{\mathrm{fP}}\right) \theta\right)$ \\
\hline 25 &,$+ M$ &,$- \mathbf{M}$ & up & $4\left(\left(1-\epsilon_{\mathrm{mP}}\right) \epsilon_{\mathrm{fB}} \theta\right), 5\left(\epsilon_{\mathrm{mP}} \epsilon_{\mathrm{fB}} \theta\right), 7\left(\left(1-\epsilon_{\mathrm{mP}}\right)\left(1-\epsilon_{\mathrm{fB}}\right) \theta\right), 8\left(\epsilon_{\mathrm{mP}}\left(1-\epsilon_{\mathrm{fB}}\right) \theta\right)$ \\
\hline 26 & $=, \mathbf{M}$ & $\because, \mathbf{M}$ & up & $5\left(\epsilon_{\mathrm{fB}} \Theta\right), 8\left(\left(1-\epsilon_{\mathrm{fB}}\right) \Theta\right)$ \\
\hline 27 &,$- \mathbf{M}$ &,$- \mathbf{M}$ & up & $5\left(\epsilon_{\mathrm{fP}} \epsilon_{\mathrm{fB}} \theta\right), 6\left(\left(1-\epsilon_{\mathrm{fp}}\right) \epsilon_{\mathrm{fB}} \theta\right), 8\left(\epsilon_{\mathrm{fP}}\left(1-\epsilon_{\mathrm{fB}}\right) \theta\right), 9\left(\left(1-\epsilon_{\mathrm{fp}}\right)\left(1-\epsilon_{\mathrm{fB}}\right) \theta\right)$ \\
\hline
\end{tabular}

It should be observed that the model description has been applied emphasizing the influence of relay reliability upon the reliability performance. The influence of e.g. a circuit breaker which is used in common by both (main and backup) protection systems can be included by treating the circuit breaker similar to the relays $\mathrm{P}$ and $\mathrm{B}$ and by making use of the functional interdependencies between relay and circuit breaker.

\section{CONCLUSIONS}

A model description has been developed as a tool to evaluate the reliability performance of components that are being protected by main and backup protection systems. The model description is quite general and the system states and transitions between system states are constructed in a systematic way which makes this approach applicable in a 
lot of situations. Both important failure modes of protection systems are dealt with: the failure to operate mode and the maltrip mode. The model description is developed with emphasis upon the preventive maintenance aspects. Its generality offers the possibility to analyse a lot of different situations.

The properties of the model description have been illustrated through an example. In the example one component $\mathrm{C}$ is being protected by a main and a (local) backup protection. Both protections are being taken out of service for preventive maintenance at the same time. Through this example it has been shown that the total costs and the optimal frequency at which preventive maintenance is carried out might be significantly influenced by the effectiveness at which the preventive maintenance is carried out.

\section{REFERENCES}

Anderson, P.M. and Agarwal, S.K., "An Improved Model for Protective-System Reliability", IEEE Transactions on Reliability, Vol. R-41, pp. 422-426, September 1992

Kumm, J.J., Weber, M.S., Hou, D. and Schweitzer III, E.O., "Predicting the Optimum Routine Test Interval for Protective Relays", IEEE Transactions on Power Delivery, Vol. 10, pp. 659-665, April 1995

Meeuwsen, I.J., W.L. Kling and W.A.G.A. Ploem, "The Influence of Protection System Failures and Preventive Maintenance on Protection Systems in Distribution Systems", in Proceedings of the 1996 IEEE/PES Winter Meeting, 96 WM 065-3 PWRD, pp. 1-8

Singh, C. and Patton, A.D., "Models and Concepts for Power System Reliability Evaluation Including Protection-system Failures", International Journal of Electrical Power \& Energy Systems, Vol. 2, pp. 161-168, October 1980

Brandao Jr, A.F, and Senger, E.C., "Reliability of Digital Relays with Self-checking Methods", International Journal of Electrical Power and Energy Systems, Vol. 15, pp. 59-63, April 1993

APM Task Force Report on Protection Systems Reliability, "Effect of Protection Systems on Bulk Power Reliability Evaluation", IEEE Transactions on Power Systems, Vol. 9, pp. 198205 February 1994

Gantner, J., F. Andersson, M. Coudray, J.P. Lamy, H. Hartmann and S. Pettissalo, "Use of Equipment Built-In Automatic Testing, Selfchecking and Monitoring with a View to Improving Reliability", CIGRE 34.03 Working Group report. Paris, France: CIGRE, 1986

Endrenyi, J., "Reliability Modeling in Electric Power Systems", John Wiley \& Sons, Chichester, 1978

Billinton, R. and Allan, R.N., "Reliability Evaluation of Power Systems", Pitman Books, Boston, 1984

Yip, H.T., Weller, G.C. and Allan, R.N., "Reliability Evaluation of Protection Devices in Electrical Power Systems", Reliability Engineering, Vol. 9, pp. 191-219, 1984

Malhotra, M., Muppala, J.K. and K.S. Trivedi, "Stiffnesstolerant Methods for Transient Analysis of Stiff Markov Chains, Microelectronics and Reliability, Vol, 34, pp. 1825 1841, November 1994

Tijms, H.C., "Stochastic Models: An Algorithmic Approach", John Wiley \& Sons, Chichester, 1994

\section{BIOGRAPHIES}

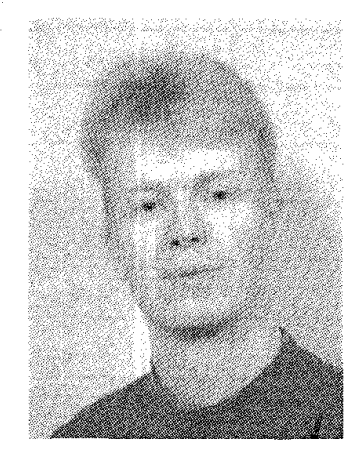

Bas Vermeulen has received a M.Sc. degree in Electrical Engineering from the Eindhoven University of Technology in 1994. He is currently working towards a Ph.D. degree at the same university in collaboration with the department of econometrics of the Tilburg University on behalf of the cooperation centre Tilburg and Eindhoven Universities. His reseach interests are mainly focussed upon reliability aspects of protection systems and the influence of preventive maintenance on the protection system reliability performance.

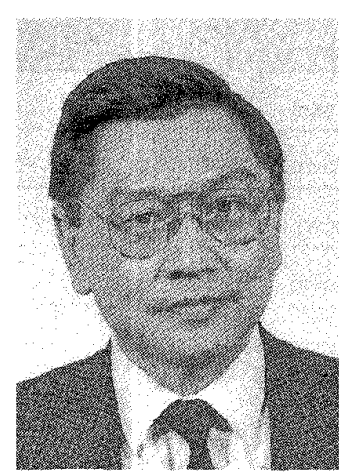

Hendro Rijanto, is professor at Eindhoven University of Technology in the Netherlands. He received his M.Sc. degree in electrical engineering from Technical University Hannover in Germany at 1970 and subsequently his Ph.D. degree from the same university in 1975 . He began working in 1970 as a development-engineer for circuit breakers at the AEG-High Voltage Institute in Kassel, Germany. After finishing the Ph.D. thesis he moved to the Power Systems Division of the same company in Frankfurt am Main, Germany, where he was responsible for the development of generator and power system protection. His further activities are now reliability analysis and application of expert systems for power system protection.

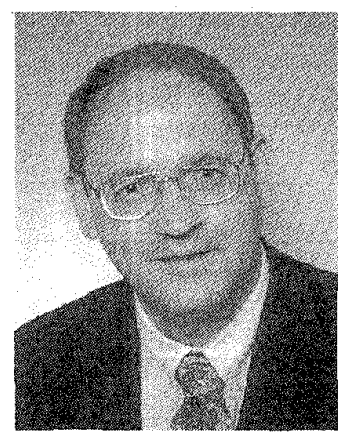

Frank van der Duyn Schouten got his Ph.D. from Leyden University in the Netherlands in 1979. The subject of his thesis was a study on the approximation of continuous time Markov decision drift processes by a series of discrete time decision processes. His research interest include inventory control models, control of queueing systems, and models for reliability and maintenance optimisation. He (co)authored about 25 papers in these areas in journals like Mor, Management Science, Operations Research, Naval Research Logistics, Zor, Ejor, Advances of Applied Probability, and Intern. Journal of Production Research. In 1980 he spent one year as research fellow at Bell Laboratories at Holmdel (N.J.). From 1987 he is professor of operations research within the School of Management and Economics at the University of Tilburg. Since 1994 he is dean of this school. For one day a week, he is affiliated as senior research fellow at the centre for mathematics and computer science in Amsterdam. 